\title{
Colorectal polyps: Detection with multi-slice CT colonography
}

\begin{abstract}
Summary. Purpose: To compare the performance of virtual and conventional colonoscopy for the detection of colorectal polyps using a multislice spiral CT scanner (MSCT). Materials and Methods: 48 patients ( 20 women, 28 men, mean age 61.5 years) with clinical indication for conventional colonoscopy were prospectively studied using a MSCT (Somatom Volume Zoom, Siemens, Forchheim). Examination was performed after standard oral preparation for colonoscopy and colonic distension with room air and i. v. butylscopolamin. Images were obtained in prone and supine position using a detector configuration of $4 \times 1 \mathrm{~mm}$, a table feed of $5 \mathrm{~mm} /$ rotation at $140 \mathrm{mAs}$ and $120 \mathrm{kV}$. Slice thickness and reconstruction increment were 3 and $1.5 \mathrm{~mm}$, respectively. CT data were assessed by two blinded radiologists on a Vitrea workstation (Vital Images, USA) using a software with multiplanar and volume-rendering capabilities. Results: 33 patients had normal findings on conventional colonoscopy. In 15 patients a total of 30 polyps and one carcinoma with stenosis were identified. MSCT-colonography identified the carcinoma and 23 polyps (77\%). 3 of 3 polyps were $10 \mathrm{~mm}$ or more (100\%), 6 of 7 were 5.1 to $9.9 \mathrm{~mm}$ (86\%) and 14 of 20 were $5 \mathrm{~mm}$ or smaller (70\%). There were 13 false positive findings for polyps ( 10 lesions $<6 \mathrm{~mm}$ in 5 patients) and no false positive finding of carcinoma. Conclusions: MSCT colonography allows accurate detection of polyps larger than $10 \mathrm{~mm}$. Compared to published results of single-slice CT, multislice CT colonography increases the rate of detection of small colorectal polyps in particular. However, false positive results still remain a problem.
\end{abstract}

Key words: polyps - computertopographie - colography multislier spiral CT

Kolorektale Polypen: Detektionsraten der Mehrschicht-CTKolographie. Ziel: Vergleich der Mehrschichtspiral-CT (MSCT)Kolographie mit der konventionellen Koloskopie in der Detektion von kolorektalen Polypen. Material und Methoden: $48 \mathrm{~Pa}-$ tienten (20 Frauen, 28 Männer, Durchschnittsalter 61,5 Jahre) mit erhöhtem kolorektalen Karzinomrisiko wurden prospektiv an einem MSCT (Somatom Volume Zoom, Siemens, Forchheim) untersucht. Zur Distension des gereinigten Dickdarms wurde Raumluft über eine rektale Sonde nach i.v. Gabe von Buscopan insuffliert. Die Bildakquisition erfolgte in Bauch- und Rückenlage mit einer Detektorkonfiguration von $4 \times 1 \mathrm{~mm}, 140 \mathrm{mAs}$, $120 \mathrm{kV}$, einem Tischvorschubsverhältnis von 1,25 sowie einem Rekonstruktionsinkrement von 1,5 bei einer Schichtdicke von $3 \mathrm{~mm}$. Die Bilddaten wurden durch zwei geblindete Radiologen

Fortschr Röntgenstr 2001; 173: 1069-1071

(c) Georg Thieme Verlag Stuttgart · New York

ISSN $1438-9029$

\author{
J. Wessling ${ }^{1}$, R. Fischbach ${ }^{1}$, D. Domagk², N. Lügering ${ }^{2}$, \\ E. Neumann ${ }^{1}$, W. Heindel ${ }^{1}$ \\ ${ }^{1}$ Department of Clinical Radiology \\ 2 Department of Gastroenterology, Internal Medicine B \\ University Clinics of Muenster
}

im Konsens an einer Vitrea workstation (Vital Images, USA) in Volumen-rendering-Technik und multiplanar ausgewertet. Die konventionelle Koloskopie erfolgte in etablierter Technik im unmittelbaren Anschluss an die MSCT-Kolographie. Ergebnisse: 33 Patienten hatten eine unauffällige konventionelle Koloskopie. Bei den übrigen 15 Patienten konnten insgesamt 30 Polypen und ein Karzinom mit Stenose identifiziert werden. In der MSCT-Kolographie wurde das Karzinom richtig identifiziert und von 30 Polypen ingesamt 23 erkannt (77\%). In der Subgruppenanalyse wurden 3 von 3 Polypen größer als $10 \mathrm{~mm}$ (100\%), 6 von 7 Polypen zwischen 5,1 und 9,9 mm (86\%) und 14 von 20 Polypen kleiner oder gleich als $5 \mathrm{~mm}$ (70\%) detektiert. Insgesamt wurden mit der MSCT-Kolographie 13 falsch positive Polypen und kein falsch positives Karzinom nachgewiesen. Schlussfolgerung: Die MSCT-Kolographie erlaubt die sichere Detektion von Polypen über $10 \mathrm{~mm}$ Durchmesser. Kleinere Befunde werden mit einer höheren Sensitivität nachgewiesen als bisher für die Einschicht-Spiral-CT angegeben. Nachteilig bleibt weiterhin die hohe Anzahl falsch positiver Befunde.

Schlüsselwörter: Polypen - Computertopographie - Kolographie - Mehrschicht-CT

\section{Introduction}

Cross sectional imaging techniques including magnetic resonance imaging (MRI) and computed tomography (CT) are increasingly being considered as alternative imaging modalities for colorectal screening [1,2]. Using thin section axial images and assigned software both techniques allow the generation of three-dimensional views of the colon, simulating those obtained with conventional colonoscopy. Since virtual colonography is relatively safe and minimally invasive it might become an attractive alternative to existing screening tests for colorectal cancer, the second most common cause of death from malignancy [3].

Currently MRI colonography is restricted by limited availability of scanners and high procedural costs. MRI as well as singleslice CT suffer from restrictions in spatial resolution and motion artefacts, which explain insufficient detection rates for masses smaller than $10 \mathrm{~mm}$ [2]. Single-slice CT requires several breath holds or a slice thickness exceeding $4 \mathrm{~mm}$ in order to scan the entire colon. A recent study comparing single-slice CT colonography and conventional colonoscopy suggests similar efficacy

Received: 5.9.2001 Accepted after revision: 10.10.2001 
for detection of polyps $6 \mathrm{~mm}$ or more in diameter (82-91\%). However, restrictions in spatial resolution resulted in a low sensitivity for polyps smaller $6 \mathrm{~mm}(55 \%)$ and frequent false positive findings [1].

Recently introduced multi-slice CT (MSCT) scanners represent a significant improvement in CT technology, combining high resolution thin slice imaging with high speed volume coverage $[4,5]$. MSCT has already been shown to improve the demonstration of colonic distention and to depict fewer respiratory artefacts [6]. The purpose of this prospective study was to evaluate the sensitivity and specificity of MSCT colonography in detection of colorectal polyps.

\section{Materials and Methods}

We prospectively studied 48 patients (20 women, 28 men, mean age 61.5 years) for colorectal cancer screening (low risk, no symptoms) or for evaluation of symptoms (including hematochezia, abdominal pain, weight loss, metastases of unknown primary) using a four slice CT scanner (Somatom Volume Zoom, Siemens AG, Forchheim, Germany). The study was approved by the ethics committee of the Medical Board Münster. From all patients a signed informed consent was obtained. The examination was performed after standard colonoscopy preparation (clear liquid diet and drinking of $4 \mathrm{~L}$ of polyethylene glycol solution the day prior to the scheduled examination), intravenous injection of butylscopolamin (Bus$\operatorname{copan}^{\circledR}$, Boehringer, Ingelheim, Germany) and colonic distension with room air to maximum patient tolerance (average of 30 bulb compressions). Distension was assessed by scout CT images, when necessary further air insufflation was performed. We obtained images in prone and supine position $[7,8]$ using a detector configuration of $4 \times 1 \mathrm{~mm}$, a table feed of $5 \mathrm{~mm} /$ rotation at $140 \mathrm{mAs}, 120 \mathrm{kV}$, and a gantry rotation time of $500 \mathrm{msec}$. Slice thickness and reconstruction increment were 3 and $1.5 \mathrm{~mm}$, respectively. Conventional colonoscopy was performed after the CT examination. The endoscopist was unaware of the CT findings. CT images were assessed by two blinded radiologists in a consensus decision using a separate workstation (Vitrea 1.1, Vital images, USA) with multiplanar and volume-rendering capabilities. The evaluation consisted of initial review of the magnified 2D transverse, sagittal, and coronare CT images in both supine and prone positions followed by endoluminal 3D images in problem solving situations. The transverse and reformatted coronal and sagittal 2D CT images werde displayed alongside the endoluminal images in a four-quadrant display format. Lesion size was determined with computed caliper measurement of the largest diameter on the $2 \mathrm{D}$ images (CT colonography) and with in vivo comparison to an open biopsy forceps (conventional colonoscopy). Size and location of polyps were recorded by using a segmental classification scheme for conventional and CT colonography (rectum, sigmoid, descending colon, left flexure, transverse colon, right flexure, ascending colon, and coecum). Using conventional colonoscopic findings as the gold standard, CT colonography findings were analyzed by direct polyp matching concerning size (size difference less than $5 \mathrm{~mm}$ ) and location (same or adjacent segment). Insufficient air distension or bowel preparation was documented for each colonic segment. Examination, data transfer, and image interpretation took about 45 minutes per case.

\section{Results}

Concerning polyps conventional colonography was normal in 33 patients. A total of 30 polyps and one carcinoma were identified in 15 patients. MSCT colonoscopy detected 23 polyps (77\%) and the carcinoma. All polyps greater than $10 \mathrm{~mm}$ were detected. 6 of 7 polyps from 9.9 to $5.1 \mathrm{~mm}$ and 14 of 20 polyps smaller than or equal to $5 \mathrm{~mm}$ were identified. 13 false positive findings affected 8 patients (Table 1 ). In 4 of these patients conventional colonscopy revealed no polyp at all. A follow-up conventional colonoscopy in one patient with three true positive and one false positive findings revealed the "false positive" lesion as a true $4 \mathrm{~mm}$ polyp.

Table 1 Multi-slice CT colonoscopy compared to conventional colonoscopy: Results (no. of polyps, in brackets no of patients) according to polyp size and occurrence of cancer. Sensitivity was calculated on a lesion-per-lesion basis, specificity was a result of an analysis on a patient-per-patient basis.

\begin{tabular}{|c|c|c|c|c|c|c|}
\hline & Total & $\begin{array}{l}\text { True } \\
\text { Positive }\end{array}$ & $\begin{array}{l}\text { False } \\
\text { Positive }\end{array}$ & $\begin{array}{l}\text { False } \\
\text { Negative }\end{array}$ & $\begin{array}{l}\text { Sensi- } \\
\text { tivity }\end{array}$ & $\begin{array}{l}\text { Speci- } \\
\text { ficity }\end{array}$ \\
\hline All sizes & 30 & $23(10)$ & $13(8)$ & $7(5)$ & $77 \%$ & $78 \%$ \\
\hline$\geq 10 \mathrm{~mm}$ & 3 & $3(3)$ & $1(1)$ & 0 & $100 \%$ & $97 \%$ \\
\hline $5.1-9.9 \mathrm{~mm}$ & 7 & $6(2)$ & $2(2)$ & $1(1)$ & $86 \%$ & $94 \%$ \\
\hline$<5 \mathrm{~mm}$ & 20 & $14 \quad(5)$ & $10(5)$ & $6(4)$ & $70 \%$ & $85 \%$ \\
\hline cancer & 1 & 1 & 0 & 0 & $100 \%$ & $100 \%$ \\
\hline
\end{tabular}

\section{Discussion}

MSCT has multiple technical advantages over single-slice CT as already shown for CT angiography or lesion detection in the liver $[9,10]$. As published previously, MSCT improves colonic distention and reduces respiratory artefacts [6]. So far results of performance in detection of small colorectal polyps with multislice CT are still lacking.

In the largest prospective study to date by Yee et al. [12] the sensitivity of single-slice CT colonoscopy for polyp detection was $90 \%$ for polyps $10 \mathrm{~mm}$ or larger, $80.1 \%$ for polyps $5-9 \mathrm{~mm}$ and $59.1 \%$ for polyps smaller than $5 \mathrm{~mm}$ (overall sensitivity $69.7 \%$ ). Our data show that MSCT colonography reliably identifies polyps greater than $5 \mathrm{~mm}$. Furthermore, the detection rate of small colorectal polyps (Fig. 1) in particular is improved compared to results previously published for singleslice CT and MRI colonography [1,2,12 - 15] and approaches the reported rate for detection of polyps smaller than $6 \mathrm{~mm}$ by conventional colonoscopy [11]. So far it is not clear whether these small lesions would justly performance of a conventional colonoscopy. Nevertheless we believe that virtual colonography should be able to identify these lesions with acceptable and comparable sensitivity to be competitive to conventional colonoscopy.

Although sensitivity for polyp detection is improved, a limitation of better size resolution with MSCT colonography is the number of false positive findings, with the majority of these lesion smaller than or equal to $5 \mathrm{~mm}$ (10 lesions $<6 \mathrm{~mm}$ in 5 patients). In our group this would result in an approximate rate of $10 \%$ of unnecessary conventional colonoscopies, consequently raising cost, and radiation exposure. However, results 

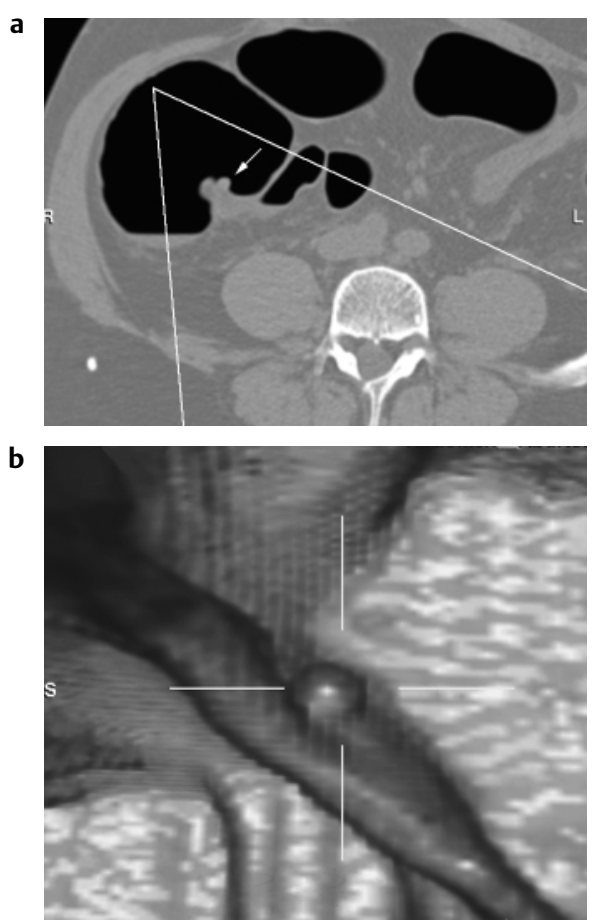

Fig. 1 Multi-slice CT colonoscopy: Axial (a) and endoluminal (b) view of a small $5 \mathrm{~mm}$ lesion (arrow) in the coecum displaying the polyp located on a fold.

of follow-up colonoscopy in one patient suggest that the specificity of MSCT colonography may be higher than reported. Indeed conventional colonoscopy misses $24 \%$ of polyps smaller than $5 \mathrm{~mm}, 27 \%$ of polyps $6-9 \mathrm{~mm}$ and $13 \%$ of polyps $10 \mathrm{~mm}$ or more [11].

In cases of missed polyps, reevaluation of the CT-data set revealed colonic collapse or inadequate bowel preparation as the most common cause for false negative results, suggesting, that observer independent factors predominantly limit accuracy of CT colonography. However, the question whether MSCT improves colonic distention has not been subject of this study.

Multiple image display techniques are available to view CT colonography data. We found virtual flights as primary diagnostic method a time-consuming approach that requires more time than the 2D approach. According to our experience polyp detection is just as effective by using 2D as by using 3D images. However, endoluminal 3D images are useful in problem solving situations (for example differentiation of small polyps on folds from nodular folds), and for demonstration as well as documentation purposes.

MSCT offers a wide range of possible scan parameter combinations. The $4 \times 1 \mathrm{~mm}$ detector configuration used in our study generates $3 \mathrm{~mm}$ slices with a slice sensitivity profile that is superior to $3 \mathrm{~mm}$ slices from a $4 \times 2.5 \mathrm{~mm}$ detector configuration or single slice CT [4]. Whether the choice of the detector configuration influences image quality and polyp detection rate has to be addressed in future work. The need for ionising radiation is a potential disadvantage of CT colonoscopy. Decreasing the tube current or acquisition of broader slices with a wider detector configuration can reduce the effective radiation dose. Therefore optimisation of scanning protocols is necessary.
Furthermore, these results from a study of symptomatic and asymptomatic patients cannot be extrapolated to a screening population. Hence, the validity of MSCT colonography has to be established in multicenter studies in persons with average risk.

\section{Literatur}

${ }^{1}$ Fenlon HM, Nunes DP, Schroy PC, Barish MA, Clarke PD, Ferrucci JT. A comparison of virtual and conventional colonoscopy for the detection of colorectal polyps. N Engl J Med 1999; 341: 14961503

${ }^{2}$ Luboldt W, Bauerfeind P, Wildermuth S, Marincek B, Fried M, Debatin JF. Colonic masses: detection with MR colonography. Radiology 2000; 216(2): 383-388

${ }^{3}$ Kronborg O, Fenger C, Olsen J, Jorgensen OD, Sondergaard O. Randomised study of screening for colorectal cancer with faecaloccult-blood test. Lancet 1996; 348: 1467-1471

${ }^{4}$ Klingenbeck-Regn K, Schaller S, Flohr T, Ohnesorge B, Kopp AF, Baum U. Subsecond multi-slice computed tomography: basics and appications. Eur J Radiol 1999; 31: $110-124$

${ }^{5}$ Rogalla P, Meiri N, Ruckert JC, Hamm B. Colonography using multislice CT. Eur J Radiol 2000; 36(2): 81 -85

${ }^{6}$ Hara AK, Johnson CD, MacCarty RL, Welch TJ, McCollough CH, Harmsen WS. CT colonography: Single- versus multi-detector row imaging. Radiology 2001; 219: 461-465

${ }^{7}$ Chen SC, Lu DSK, Hecht JR, Kadell BM. CT colonography: value of scanning in both supine and prone position. Am J Roentgenol 1999; 172: 595 - 599

${ }^{8}$ Fletcher JG, Johnson CD, MacCarty RL, Welch TJ, Hara AK, Reed JE. CT colonography: overcaming the problems of collapse and colonic fluid (abstr). Radiology 1998; 209((P)): 296

${ }^{9}$ Rubin GD, Schlau MC, Leung AN, Kee S, Logan LJ, Sofilos MC. Aorta and iliac arteries: single versus multiple detector-row helical CT angiography. Radiology 2000; 215: 670-676

${ }^{10}$ Weg N, Scheer MR, Gabor MP. Liver lesions: improved detection with dual-detector-array CT and routine $2.5-\mathrm{mm}$ thin collimation. Radiology 1998; 209: 417-426

${ }^{11}$ Rex DK, Cutler CS, Lemmel GT, et al. Colonoscopic miss rates of adenomas determined by back-to-back colonoscopies. Gastroenterology 1997; 112: 24-28

${ }^{12}$ Yee J, Akerkar GA, Hung RK, Steinauer-Gebauer AM, Wall SD, McQuaid KR. Colorectal Neoplasia: Performance characteristics of CT colonography for detection in 300 patients. Radiology 2001; 219: 685-692

${ }^{13}$ Dachman AH, Kuniyoshi JK, Boyle CM, et al. CT colonography with three-dimensional problem solving for detection of colonic polyps. Am J Roentgenol 1998; 171: 989-995

${ }^{14}$ Hara AK, Johnson CD, Reed JE, et al. Detection of colorectal polyps with CT colonography: initial assessment of sensitivity and specificity. Radiology 1997; 205: 59-65

${ }^{15}$ Rex DK, Vining D, Kopecky K. An initial experience with screening for colon polyps using spiral CT with and without CT colonography (virtual colonoscopy). Gastrointest Endos 1999; 50: 309-313

Dr. med. Johannes Wessling

Department of Clinical Radiology

University of Muenster

Albert-Schweitzer-Straße 33

48129 Münster

Tel. + 49-251-8347302

Fax $+49-251-8347312$

E-mail: weslingj@uni-muenster.de 